\title{
Abandonamos a sala da universidade: uma opção decolonial no estágio de inglês e na formação docente crítica
}

\section{We Left the University Classroom: A Decolonial Option in the English Practicum and in Critical Teacher Education}

\author{
Mariana R. Mastrella-de-Andrade* \\ *Universidade de Brasília (UnB), Brasília, Distrito Federal / Brasil \\ marianamastrella@gmail.com
}

https://orcid.org/0000-0002-0539-0293

\begin{abstract}
RESUMO: Neste artigo, discuto um semestre de estágio supervisionado em inglês desenvolvido integralmente em uma escola pública. Adoto uma perspectiva decolonial (MIGNOLO, 2014), na busca por romper com colonialidades do saber, do poder e do ser na relação universidade-escola para a formação docente (BORELLI, 2018; PESSOA, 2018), objetivando entender como vivenciamos essa tentativa de decolonialidade, com foco em três aspectos: a maneira como o estágio é estruturado, meu papel como professora formadora e o papel dos sujeitos da escola. Esta pesquisa qualitativa e interpretativista (DENZIN; LINCOLN, 2005) foi desenvolvida com material empírico gerado através de diários, entrevistas, notas de campo e trocas de mensagem por e-mail e WhatsApp. As discussões mostram como iniciamos um rompimento com a estrutura tradicional do estágio e reconstruímos saberes e nossas identidades a partir da vivência na escola como ecologia de saberes (SOUSA SANTOS, 2007).
\end{abstract}

PALAVRAS-CHAVE: formação docente de inglês; estágio supervisionado; decolonialidade.

ABSTRACT: In this article, I discuss a one-semester English Practicum experience held entirely inside a public school. I adopt a decolonial perspective (MIGNOLO, 2014) in an attempt to break with colonialities of power, knowledge, and being in the university-school relationship for language teacher education (PESSOA, 2018; BORELLI, 2018), aiming to understand how we live this attempt in terms of three aspects: the way the English Practicum is structured, my role as a teacher educator, and the role of the school subjects. This qualitative, interpretive (DENZIN; LINCOLN, 2005) research was developed with empirical material generated through diaries, interviews, field notes, and email and WhatsApp messages. The discussions show how we started 
to break with the traditional structure of the English Practicum and how we reconstructed our knowledges and our identities by living and understanding the school as an ecology of knowledges (SOUSA SANTOS, 2007).

KEYWORDS: English teacher education; English practicum; decoloniality.

If we have been over-exposed to and over-socialized in specific European Enlightenment ideals, and if we need to amplify our constellations of meaning, this starts with an acknowledgement of our own inadequacy to even recognize other possibilities - our epistemic blindness.

Andreotti (2013)

\section{Introdução}

Naquele dia, quando finalmente ficou firmado o acordo de que o estágio supervisionado em Letras-Inglês poderia ser feito naquele centro de ensino médio próximo à universidade, me despedi do diretor e de Sueli, uma das professoras de inglês da referida escola, com um misto de alegria e tensão. A alegria foi por poder abandonar a sala de aula na universidade e receber as/os professoras/es estagiárias/os na própria escola desde o primeiro dia do semestre letivo, que iniciaria dali a dois meses, ao contrário da tradicional divisão dos "estudos teóricos" do estágio feitos em sala de aula na universidade e a "parte prática" na escola. Eu não precisaria mais dizer "vamos à escola", pois já estaríamos nela; afinal, essa era a ideia: nos formarmos professoras/es na e para a escola, que agora nos cederia uma sala de aula para nossos estudos, planejamentos e práxis docente de inglês. A tensão, por sua vez, veio praticamente pela mesma razão: agora que estaríamos na escola, de que maneira o estágio supervisionado poderia ser reinventado? O que era preciso fazer para que sair do ambiente encastelado da universidade não fosse uma mera mudança geográfico-espacial? Como eu poderia vivenciar e apoiar vivências de formação docente naquele semestre letivo diferentemente de quando o estágio supervisionado era organizado por mim com um terço das aulas na universidade, para estudos e planejamentos, e dois terços delas especificamente para observação e regência na escola pública?

A epígrafe que abre este texto diz muito do que tenho vivenciado. Como salienta Andreotti (2013), tendo sido educadas/os nos preceitos 
modernos do Iluminismo, segundo os quais conhecimento e razão são as chaves para o alcance do sucesso na educação, possuímos muitas vezes uma "cegueira epistêmica", que nos faz indagar: como enxergar novas possibilidades? Como reinventar o que já fazemos, optando por uma perspectiva decolonial de formação docente (ANDREOTTI, 2013; BORELLI, 2018; MASTRELLA-DE-ANDRADE; PESSOA, 2019; SILVESTRE, 2017)? Se uma temporada nova estava para começar, como pensá-la para além dos binarismos que sustentam muitas vezes nosso trabalho (universidade e escola; teoria e prática; língua estrangeira e língua materna, entre outros)?

Entendo que a noção de decolonialidade requer o reconhecimento de nossas sociedades enquanto espaços de consequências insistentes dos "distintos dispositivos de colonização, de dominação, de subjugação e invisibilização que atentam contra outras formas de conhecer, ser e estar diferentes (e subalternizadas) ao que é colocado pela matriz colonial de poder", como argumenta Mignolo (2014, p. 61-62, tradução nossa). Quijano (2005, p. 107), por sua vez, usa o termo colonialidade do poder para se referir justamente à maneira como, após o término das administrações coloniais, são mantidos elementos de "colonialidade no padrão de poder hoje hegemônico". Ele se refere a esses elementos como dois eixos fundamentais de um novo padrão de poder a partir da colonização: a ideia do padrão de raça para diferenciar conquistados e conquistadores, "uma supostamente distinta estrutura biológica que situava uns em situação natural de inferioridade em relação a outros", e a "articulação de todas as formas históricas de controle do trabalho, de seus recursos e de seus produtos, em torno do capital e do mercado mundial" (QUIJANO, 2005, p. 107, tradução nossa).

Walsh (2010a, p. 221) também entende a matriz colonial como um sistema racial-classificatório e hierárquico que estabelece o homem branco como modelo de identidade e o conhecimento moderno europeu como universal, desprezando, assim, outras racionalidades epistêmicas. Nesse sentido, ressalto duas críticas decoloniais importantes para as discussões que aqui pretendo desenvolver. Em primeiro lugar, parto do princípio de que a racionalidade eurocentrada é, como ressalta Walsh (2010a, p. 221), euroeua-centrada, isto é, inclui países do norte que têm desenvolvido políticas internacionais de colonização e, sobretudo, de manutenção da colonialidade mesmo após o fim das administrações coloniais (GROSFOGUEL, 2008, 
p. 125). Em relação ao ensino e à formação de professores/as de inglês, a colonialidade tem sido exercida e mantida de maneiras bastante visíveis, sobretudo através da epistemologia do falante nativo, à qual a produção de livros didáticos, de preparação para ensinar, de usos da língua, de metodologia, de política linguística, de currículo, de agenda de pesquisas etc. são insistentemente atreladas (KUMARAVADIVELU, 2012, p. 15). Como consequência, os saberes e as necessidades locais são invisibilizados; uma opção decolonial, portanto, busca escutá-los, não os entendendo como inexistentes.

Em segundo lugar, a classificação racial advinda da colonização permanece ainda em e entre nós (QUIJANO, 2005). Sendo percebida como branca, carrego em mim privilégios e acessos que a pessoas negras/os e de outras raças são negados. E não somente isso; trago também a constante possibilidade de entender o mundo através da branquitude, em que "o branco assume papel de normatividade e neutralidade" (ANDRADE, 2018, p. 244). Tomo, então, por princípio que o sistema escolar e educacional, ao qual pertencem a formação docente e o ensino de língua inglesa de que falo aqui, é espaço de reprodução de sistemas de valores e conhecimentos brancos, europeus, colonialistas (ANDRADE, 2018; GOMES, 2012). Por essa razão, lançar um olhar decolonial sobre a formação docente requer entendê-la como espaço epistemológico corporificado. Para Mignolo (2014, p. 63), a colonialidade está em todas as partes e não estamos fora dela, já que "uma análise do padrão colonial de poder é sempre uma análise de nós mesmos/as". É nesse sentido que relato e discuto aqui, como mostro posteriormente, a maneira como tentamos subverter nossas práxis de estágio na formação de professoras/es de inglês.

Concordo com Quijano (1998, p. 234) que uma subversão por si só não é suficiente para produzir uma nova alternativa; entretanto, ele mesmo ressalta que uma subversão é um primeiro passo para uma real mudança de hegemonia. Nesse sentido, a maneira como construímos o estágio supervisionado em inglês buscou romper com formas coloniais de fazer formação docente, com tentativas de operar uma redistribuição democrática do poder e de resistir a uma reconcentração de poder. Assim, discuto neste artigo uma experiência de formação docente através da disciplina de estágio supervisionado em inglês integralmente desenvolvida dentro de uma escola pública, em uma perspectiva decolonial, no que se refere a três aspectos: à maneira como o estágio é estruturado, ao meu papel como 
professora formadora e ao papel dos sujeitos da escola pública na formação de professoras/es de inglês.

Ressalto aqui que a experiência que todas/os nós (professoras/ es formadoras/es, professoras/es estagiárias/os e alunas/os da escola) encontramos na vivência do estágio, embora limitada por normativas burocráticas, engessada por horários incompatíveis e recursos escassos, desacelerada por ideais inatingíveis e desmotivada por relações nem sempre amigáveis, oportunizou agências imprevisíveis. Essas, por sua vez, transformaram situações fadadas ao aparente fracasso em possibilidades singulares de adentrar a formação docente e o ensino de inglês na escola de maneira positivamente marcante. É nessa perspectiva e compreensão que busco, neste artigo, relatar a experiência de um semestre letivo de estágio supervisionado em inglês ocorrida integralmente dentro de uma escola pública.

\section{A organização do estágio supervisionado integralmente dentro da escola e o contexto da pesquisa}

O que aqui chamo de integralmente dentro de uma escola se refere à maneira como o estágio foi organizado e estruturado em conjunto com uma escola pública do Distrito Federal, que incluiu a proposta do estágio em seu Projeto Político Pedagógico, firmando uma parceria com a formação docente em Letras-Inglês na Universidade. Dessa maneira, uma sala da escola foi cedida a nós, onde podíamos nos reunir toda sexta-feira das $8 \mathrm{~h}$ às $12 \mathrm{~h}$, horário da disciplina, além de termos livre acesso para trabalhar com as duas professoras de inglês da escola e, assim, desenvolvermos projetos de ensino para as turmas de inglês do ensino médio dos turnos matutino e vespertino atendidos naquela instituição.

Logo no início das matrículas na universidade, as/os estagiárias/os foram avisadas/os sobre para onde deveriam se dirigir desde o primeiro dia do semestre acadêmico. $\mathrm{Na}$ escola, podíamos nos organizar como quiséssemos. Os encontros do primeiro mês do semestre, que foi de agosto a dezembro, ocorreram naquela sala de aula da escola, onde priorizamos estudar sobre ensinar inglês a partir de uma perspectiva de letramentos sociais (KLEIMAN, 2005). Os encontros foram organizados em apresentações e discussão dos seguintes textos: Orientações Curriculares para o Ensino Médio (BRASIL, 2006), Preciso "ensinar" o letramento? Não basta 
ensinar a ler e a escrever? (KLEIMAN, 2005), "O ensino de leitura em língua estrangeira na escola: uma proposta de letramento" (SCHLATTER, 2009) e também "Para uma redefinição de Letramento Crítico: conflito e produção de significado (MENEZES DE SOUSA, 2011).

A leitura e discussão desses textos iniciais teve como foco entender o ensino de inglês na perspectiva dos letramentos sociais, em que língua é vista como prática social, não como transmissão de regras de um sistema fixo ou fechado e, portanto, como espaço para formação cidadã crítica e responsável na sociedade (KLEIMAN, 2005; MENEZES DE SOUSA, 2011; PESSOA, 2018). Assim, além dos quatro textos inicialmente citados, as/os estagiárias/ os se dividiram também em grupos para apresentar e discutir outros quatro textos publicados na Revista Bem Legal, ${ }^{1}$ com enfoque em ensino de inglês e letramentos. Estes foram os artigos que lemos e discutimos, que trazem relatos de projetos desenvolvidos em sala de aula de inglês na escola pública: "Culture and consumerism in the classroom" (PUREZA; ZANIOL, 2016), "Heroes and villains: a report of a project to teach English for teenagers" (GASPERI, 2016), "What is the soundtrack of my life? - An internship in group 92" (NUNES, 2016) e "Hi, future me! A time in class to think about past, present and future, in English" (SILVA; SANTIAGO, 2016).

Enquanto estivemos na escola, buscamos nos organizar de modo a vivenciar o cotidiano da comunidade escolar naquele semestre. Éramos 25 pessoas do curso de Letras-Inglês ali: 16 professoras estagiárias (com idades entre 20 e 32 anos), oito professores estagiários (com idades entre 22 e 39 anos) e eu, professora formadora. Com exceção do meu, todos os nomes que aparecem no material empírico a seguir são fictícios, sugeridos pelas/ os próprias/os participantes. No horário do recreio da escola, nós também fazíamos nosso intervalo, lanchávamos, conversávamos com as pessoas e observávamos a rotina da escola. Durante nossos estudos e discussões, que precederam o início dos projetos de regência nas diversas turmas, tivemos por duas vezes a presença das/os próprios alunas/os da escola, além das

\footnotetext{
${ }^{1}$ A Revista Bem Legal é uma "publicação eletrônica semestral, idealizada por alunas/os e professoras/es do Instituto de Letras da UFRGS", para "trocar experiências e vivências bem-sucedidas em sala de aula", "estabelecer parcerias para articular o que é produzido no Instituto de Letras e nos cenários escolares" e "aproximar o professor da educação básica e a comunidade acadêmica”. Informações retiradas da página eletrônica da revista. Disponível em: http://www.ufrgs.br/revistabemlegal/sobre-a-revista. Acesso em: 20 out. 2018.
} 
professoras de inglês, convidadas/os para que participassem conosco do que estávamos conversando. Queríamos muito saber a opinião, a visão, a experiência delas/es, já que era sobre isso que os textos que líamos e os assuntos de que falávamos tratavam: um ensino que se fizesse relacional e relevante, isto é, que tivesse a ver com o que as/os alunas/os desejam e com o que de fato consideram relevante para suas vidas, a fim de não dissociar a língua inglesa de suas realidades. A tentativa dessa empreitada foi buscar romper com a divisão geopolítica entre teoria e prática, que marca a teoria (enquanto conhecimento) como objeto da universidade e prática enquanto espaço para consumo da teoria na escola, como discute criticamente Mateus (2009). O desejo, ao investir no abandono dos muros trincados da universidade e vivenciarmos o chão da escola para todas as ações concernentes à disciplina naquele semestre, foi construir um espaço mais democrático de formação de professoras/es de inglês e, assim, romper com abissalidades que nos impedem de assumir nossas ignorâncias (SOUSA SANTOS, 2007) e de aprender com outros saberes. Apesar desse desejo e das ações empreendidas, conflitos, dificuldades, contradições, incoerências e inconsistências nos acompanharam em todo o processo, conforme relato e discuto neste artigo.

O estágio integralmente feito na escola pública foi organizado da seguinte forma: cinco encontros de estágio (para estudos e planejamentos), 40 horas de regências de aulas de inglês, dois seminários de estágio (no auditório da escola, com duração de quatro horas cada) para compartilhar as experiências, discutir e avaliar o trabalho de modo geral. Durante os quatro primeiros encontros do estágio, estudamos juntas/os sobre o que é ensinar inglês numa perspectiva para letramentos e começamos a planejar projetos e aulas de inglês para a escola, a partir das orientações que nos davam as professoras de inglês, Sueli e Marde. Licenciadas em Letras, Marde já atuava como professora de inglês da Secretaria de Educação do Distrito Federal há 15 anos (desde 2012) e Sueli há apenas dois anos.

Esta é uma pesquisa qualitativa de cunho etnográfico (DENZIN; LINCOLN, 2005). O material empírico discutido aqui foi gerado a partir de: diários (feitos tanto por mim, professora formadora, quanto pelas/os professoras/es estagiários/as), gravações em áudio de aulas, de seminários de discussão e de avaliação do estágio, entrevistas com professoras da escola e professoras/es estagiários/as, notas de campo realizadas por mim ao longo do semestre, mensagens via correio eletrônico (e-mail) e por 
telefone (WhatsApp). Tanto as professoras de inglês da escola quanto as/os professoras/es estagiários/as cujas falas aparecem neste trabalho assinaram termos de consentimento autorizando seu registro e uso para discussões em pesquisas acadêmicas.

A organização e discussão do material empírico aqui se dá em uma perspectiva interpretativista de pesquisa (MOITA LOPES, 1994), segundo a qual pesquisadoras/es são agentes sociais e, como tais, atribuem significados culturais sobre a pesquisa. Nesse sentido, chamo o semestre letivo que aqui discuto de temporada, organizada em três episódios. Busco, assim como Süssekind Veríssimo (2007, p. 66), "montar argumentos a partir das brincadeiras - intelectuaisbraçais - de juntar e separar palavras e assim chamar a atenção para as dicotomias fundantes do pensamento ocidental". Nessa "brincadeira", concordo com a autora sobre a importância de pôr em relevo "o maniqueísmo muitas vezes naturalizado nas expressões e pensamentos contemporâneos que foram amalgamados na cultura ocidental a proveito da dogmatização da ciência e de seus fazedores". Embora eu chame essa experiência de temporada e descreva, a seguir, alguns de seus episódios, não creio que uma trama vivida por tantas pessoas possa ser contada de forma única, com início e fim. Acredito, no entanto, que diferentes episódios, mesmo sem relação cronológica, possam mostrar como olho para essa experiência, como seus fragmentos me confrontam e como nossas práxis (minha, das/os professoras/es estagiárias/os e das professoras de inglês da escola) foram por vezes coloniais, decoloniais, conflituosas, paralisantes e, ao mesmo tempo, propulsoras.

\section{Episódio 1: "Estava tudo um caos"}

No primeiro encontro da disciplina de Estágio Supervisionado em Inglês naquele semestre, entrei para a sala onde a escola havia designado ser a "sala do estágio de inglês" e preparei ali o projetor que eu havia levado, o computador, arrumei as cadeiras e fiquei aguardando as/os professores/ as estagiárias/os. Como ainda estava cedo, saí e conversei com a professora de inglês do matutino, Sueli, e com o diretor da escola, que me disseram que iriam estar conosco naquele dia também em alguns momentos. Eu usava um crachá da universidade, que me identificava como professora. Confeccionei crachás para os/as professores/as estagiários/as, para que fossem identificadas/os igualmente pelos nomes ao adentrar o espaço da escola. A ideia era formalizarmos o que precisava ser tratado com 
formalidade, mostrando assim respeito por aquele local que nos integrava. No entanto, essa decisão não era sem conflitos: um crachá marcava uma hierarquia, exatamente com a qual eu propunha romper. Foi dessa maneira que, desde o primeiro dia, questionei meu papel e minha identidade como professora formadora em busca de uma opção decolonial.

Como era o dia 11 de agosto, Dia do Estudante, a escola estava organizada em oficinas, ministradas pelos/as alunos/as dos segundos e terceiros anos do ensino médio (os anos ofertados pela manhã). Assim que as/os professoras/es estagiárias/os chegaram, nos reunimos na sala destinada a nós, expliquei sobre os significados da parceria com aquela escola e fiz uma dinâmica de apresentação inicial. Em seguida, propus que saíssemos para participar das oficinas que estavam acontecendo na escola, vivenciando aquele espaço naquela manhã, e voltássemos após o sinal do intervalo para aquela sala, que seria daí em diante a sala do estágio.

Ao voltarmos, após aproximadamente uma hora, nos reunimos novamente na sala do estágio e perguntei o que tinham visto pela escola. Reporto aqui parte do diálogo que tivemos naquele momento:

Mariana: Então, gente? Hoje é dia do estudante, vocês viram, né? Lena: Nossa, fiquei encantada. Os alunos são muito articulados. Conversei com uns que me espantaram.

Khal Drogo: Estava muito organizado, professora. As oficinas. Organizadas.

Agnes: Tinha uns alunos na oficina que eu fui, aí eu me apresentei, eles foram muito simpáticos comigo, me receberam superbem. Nossa, fiquei surpresa, parece que a gente está sendo bem recebido aqui, professora.

Mariana: Que bom, né?

Lena: Professora, eu fui na oficina que está acontecendo bem na sala de inglês. Vocês viram a sala de inglês? Tem uma sala própria. Só para inglês. Tinha até uns cartazes em inglês na parede. Cartaz de alunos. (Encontro do estágio em 11/08/2017, audiogravação).

Chama-me a atenção, ao olhar para essa interação que tivemos, a maneira como a escola é descrita: "organizada", com "alunos articulados", "simpáticos" e que "receberam superbem". São todas características positivas, mas que parecem ter deixado as/os professores/as estagiárias/ os surpreendidas/os. Entretanto, por que a surpresa? Não seria esse o esperado? Qual a visão que temos da escola antes de nos aproximarmos dela? 
Que verdades são construídas a todo o tempo sobre os sujeitos da escola pública da educação básica no Brasil e, em especial, sobre como o ensino de inglês envolve esses sujeitos? Não é incomum encontrarmos relatos sobre desmotivação e indisciplina atribuídas a alunas/os de inglês nas escolas públicas (COELHO, 2011). São discursos que constroem as identidades dos sujeitos da escola (DAMACENA; MASTRELLA-DE-ANDRADE, 2017) e do próprio espaço escolar (LIMA; SALES, 2007). O distanciamento entre escola e universidade confirma e mantém, muitas vezes, esses discursos. $\mathrm{Na}$ interação transcrita acima, expressões como "fiquei encantada", "me espantaram" e "fiquei surpresa", ditas por Lena e Agnes sobre o que viram na escola e como as/os alunas/os ali interagiram com elas, mostram que possivelmente o esperado dos sujeitos e da estrutura da escola era bastante diferente do que elas de fato encontraram. São transformações nas relações que mantemos com a escola - em nossas compreensõesafetos sobre esse espaço - que só podem se dar no chão da escola, isto é, só podem ocorrer a partir do momento que vivenciamos, de modo relacional, experiências com quem lá está. Segundo Blommaert (2005, p. 207, tradução nossa),

Quanto maior a distância, mais gerais e menos precisas as nossas categorias se tornam. Nós tendemos a ter categorias extremamente sutis e refinadas para o que está mais próximo de nós, mas podemos ter que recorrer a estereótipos simples, exasperando a incapacidade de perceber todos os tipos de diferenças, assim que nos afastamos.

Nesse sentido é que acredito que a distância mantida entre a universidade e a escola é fundamental para determinar a identidade da formação que docente que fazemos. Quanto mais distante, menos chances temos de entender a sala de aula de inglês no contexto escolar, de nos prepararmos para recebê-la e para nos entendermos recebidas/os nela e por ela.

Entretanto, acredito também que uma aproximação geográficoespacial não é, por si só, suficiente para transformar os discursos que constroem as verdades sobre a escola. Em minha experiência, a ida à escola para o cumprimento de atividades burocráticas do estágio (observar, ministrar uma aula etc.) não é o bastante para romper com a distância, podendo, inclusive, reforçar ainda mais os estereótipos. É preciso um chegarafetivo que se traduza no que decido chamar de adentrarparaficar, que permita espírito aberto para vivenciar o espaço do outro. Isso implica dizer 
que a escola, embora localizada em nossa cidade, em meio aos caminhos por que passamos em nosso vaivém pela cidade, se constitui na hibridez de um espaço que não é o meu totalmente e que não conheço: não posso adentrá-lo a partir de minha lógica do que ele deveria ser, o que também não significa dizer que preciso aceitá-lo como ele esteja. Adentrar a escola para a formação docente crítica e decolonial implica se ver em um novo espaço. Implica abertura de espírito para entendê-lo como um espaço outro, em um momento outro, com pessoas outras. É a abertura de que fala Walsh (2010b, p. 78, tradução nossa, grifo da autora) sobre os significados de uma interculturalidade crítica, entendida como

estratégia, ação e processo contínuo de relacionamento e negociação entre, em condições de respeito, legitimidade, simetria, equidade e igualdade. Mas ainda mais importante é a sua compreensão, construção e posicionamento como um projeto político, social, ético e epistêmico - de saberes e conhecimentos -, que afirma a necessidade de mudar não apenas as relações, mas também as estruturas, condições e dispositivos de poder que mantêm a desigualdade, inferiorização, racialização e discriminação.

Para isso, o ato de adentrar a escola na formação docente não pode ser corriqueiro, como quem adentra qualquer lugar que seja apenas um espaço de passagem para devidos fins (como adentrar uma sala de espera, onde o que se espera poder fazer ali é apenas esperar). E isso só é possível no "adentramento" por inteiro. Adentrar apenas fisicamente, como quem vai à escola para pôr em prática ou observar o que aprendeu na universidade, com tarefas burocráticas esquematizadas que demandam algumas visitas pontuais para serem realizadas, tem resultado em um movimento de distanciamento, estereotipação e preconceitos (BORELLI, 2018; IFA, 2014). É preciso o que chamo aqui de um adentrarparaficar: adentrar para pertencer, ainda que por pouco tempo, buscar para si algum lugar. Essa foi a opção nesse semestre de estágio integralmente realizado dentro da escola. Quando chegamos à escola, começamos a ver que nossos trabalhos ocorreriam ali do início ao fim da disciplina de estágio. As professoras de inglês, Sueli e Marde, com quem começávamos a interagir, estariam conosco até o final. Cada um e cada uma de nós começou a se ver ali em algum tipo de integração com aquele espaço, pois, para começar, estaríamos ali de agosto a dezembro. Por isso é que Agnes disse: "parece que a gente está sendo bem recebido aqui", na 
interação anteriormente transcrita. Ao dizer "está sendo", ela evidencia um processo, uma construção do ato de ser bem recebida, ainda não concluído. Ela não diz categoricamente que foi ou não foi bem recebida. Ela "está sendo" recebida, isto é, se vê, de alguma forma, envolvida em um processo de recebimento iniciado. Esse processo é possível, a meu ver, em função de um estar na escola para além do mero cumprimento de atividades estanques. Estar na escola para vivenciá-la, como quem vai permanecer durante todo o semestre (já que a proposta foi que nós ficássemos ali para toda e qualquer proposta do estágio, desde nossas reuniões de estudo, nosso momento de lanche, nossas aulas ministradas, os planejamentos pretendidos, as aplicações e correções de provas etc.), pode nos colocar em um processo de vir a fazer parte. É nesse sentido que me refiro a adentrarparaficar.

No segundo encontro do estágio iniciamos discussões sobre o texto que eu havia indicado para leitura e tivemos a presença de alunas/os das turmas de inglês do segundo ano $\mathrm{C}$ conosco, a convite nosso. Elas/es participaram com opiniões sobre como aprendiam inglês e também relataram dificuldades da aprendizagem na escola pública. Ao tocar o sinal para o início do recreio, saímos para um intervalo e propus que andássemos pela escola e buscássemos interagir com os/as alunos/as enquanto lanchávamos. Assim que tocou o sinal do fim do recreio, nos reunimos novamente na sala do estágio e a professora de inglês, Sueli, nos perguntou se haveria duas ou três pessoas que poderiam auxiliar os/as alunos/as da sua turma em uma atividade que fariam. Três professoras/es estagiárias/os se voluntariaram e foram para a turma dela, enquanto o restante de nós permanecemos com as discussões dos textos sobre ensino de línguas na perspectiva dos letramentos. Ao retornarem, perguntei como havia sido a participação na atividade da professora de inglês, ao que Rui e Lena responderam:

Rui: Ai, professora, quando a gente chegou estava tudo um caos. Quando a gente chegou lá os alunos estavam todos em pé, tudo conversando, falando ao mesmo tempo. Ninguém senta, professora. A Sueli também fica o tempo todo conversando com os alunos.

Lena: Professora, a Sueli fica super de boa. É impressionante. Os alunos brincam com ela fora de hora, ela leva na boa, não estressa. Tem que ser assim, Rui, pra não achar tudo um caos. Eu gostei de participar lá da aula dela. A gente ajudou alguns alunos a fazer as tarefas, exercícios lá que ela pediu e valia nota.

Mariana: Por que a gente acha a sala um caos? O que guia nosso olhar? 
Lue: Eu acho que a gente vê um caos porque a gente espera uma ordem, né? Aí não tem a ordem que a gente quer, a gente acha que está um caos.

Rui: Ah, não, gente, que estava um caos estava

(Encontro do estágio em 18/08/2017, audiogravação).

O adentrarparaficar na escola, como tenho discutido até aqui, implica um encontro intercultural crítico (WALSH, 2010b), que pode promover novas compreensõesafetos sobre esse espaço educacional. Entretanto, isso não significa romantizar a formação docente que ocorre dentro da escola, já que ela é constituída a partir de confrontos e conflitos (BORELLI, 2018; SILVESTRE, 2017). Se a distância evidencia uma perspectiva colonialista na relação entre universidade e escola, como o colonizador que possui o bem que o colonizado não tem e que, assim, parte com a missão de entregá-lo, sem querer entender quem são os sujeitos daquele espaço, quais são suas perspectivas culturais, identitárias e de desejo (SOUSA SANTOS, 2009), o adentrarparaficar na escola implica a possibilidade de todas/os nós, em formação, termos nossas compreensõesafetos questionadas. É nesse sentido que Rui vê "o caos" ao participar da aula naquele dia.

Em minha experiência à frente da disciplina de Estágio Supervisionado nos últimos pelo menos dez semestres, o "caos" de que fala Rui aparece com frequência nos relatos finais sobre a experiência das/os professoras/es estagiárias/os. Por ser ao final do semestre, o que fazemos nesses relatos é discutir nossas visões sobre indisciplina nos últimos encontros avaliativos, já no espaço físico da universidade, sem a chance de retornarmos à escola enquanto ainda estamos no estágio. Entretanto, a afirmação de Rui aparece aqui no segundo encontro da disciplina. Se sua observação do "caos" se deu ali, foi ali mesmo que ele recebeu um contraponto ao que observou, feito por Lena e Lue: "a gente acha que está um caos porque a gente espera uma ordem". Que “ordem”, afinal, esperamos? De onde vem nossa ideia de “ordem"? De acordo com Brenneisen e Tarini (2008, p. 95), a indisciplina nas escolas públicas e privadas precisa ser vista a partir de questões identitárias: muitas vezes as/os alunos não são compreendidas/os em suas identidades, "em suas diferenças e em suas especificidades", sendo categorizadas/os a partir de um olhar que as/os marginaliza em função da diversidade que as / os constitui. Nesse sentido, Lena e Lue questionam a visão de Rui, abrindo espaço para que olhares diferentes sobre as/os mesmas/os alunas/os possam ser considerados: talvez o problema não estivesse simplesmente no 
"caos" descrito, mas também na "ordem" esperada. Além disso, estávamos ainda iniciando o semestre letivo do estágio. Rui ainda teria a oportunidade de ver suas compreensõesafetos do "caos" da sala de aula vivenciados em outros momentos, possivelmente de outras formas.

\section{Episódio 2: "Nós não vamos observar primeiro?"}

De maneira geral, os estágios supervisionados em língua inglesa são iniciados por observações de aula pelas/os estagiários/as, feitas na escola, com a ideia de que primeiramente observamos quem ensina para então podermos aprender como ensinar. Segundo os documentos nacionais que regem a formação docente, como as Diretrizes Curriculares Nacionais para a formação de professoras/es (BRASIL, 2015, p. 10), dentre as ações previstas para a formação estão: “observação, análise, planejamento, desenvolvimento e avaliação de processos educativos e de experiências educacionais em instituições educativas", o que mostra que a ação específica de observar é considerada como parte do processo de formar docentes.

À medida que o modelo reflexivo de formação docente (SCHON, 1983; SMYTH, 1992; ZEICHNER; LISTON, 1996) ganhou proeminência sobre o "modelo do artesão" e o "modelo tecnicista" (MARQUES, 2004) e obteve abrangência em grande parte do mundo no que diz respeito à formação de professoras/es, tornando o termo "reflexão" jargão da área e preceito fundamental para o trabalho da/o profissional professor/a (ZEICHNER, 2008), observar aulas continuou fazendo parte da formação e do processo de desenvolvimento docente, no intuito de abrir caminho e dar espaço para a continuidade da reflexão. Para refletir, porém, a/o professor/a deveria observar a partir de critérios, isto é, a partir de pressupostos teóricos sobre o que é ensinar. Assim, a observação em geral deve ser feita com um guia prévio sobre que aspectos devem ser observados (RICHARDS; LOCKHART, 1996). Entendo que um guia prévio de observação de aulas, entretanto, é construído a partir de concepções preestabelecidas que, de alguma maneira, fundamentam o ato de ensinar. Isso significa dizer que a observação, ainda que se pretenda isenta ou livre, nunca é dissociada dos sujeitos que observam e dos sujeitos observados.

Estando na escola integralmente naquele semestre decidi que não faríamos a tradicional observação, a tradicional ida às salas de aula para sentar e assistir a uma aula da professora de inglês e registrar a descrição do que ocorresse ali. Embora haja o reconhecimento do papel da observação 
na formação de professoras/es, vários são os relatos de dificuldades quando a universidade, no papel exclusivo de instituição formadora (BORELLI, 2018), se aproxima para observar a escola. Biazi, Gimenez e Stutz (2011, p. 59) relatam que, quando se dirigiam a professoras/es da escola pública para que aceitassem estagiárias/os, encontravam posturas tais como: "total repúdio à nossa solicitação de responder o questionário sobre observação; resistência em abrir espaço para as práticas de estágio e negação da presença dos estagiários para a fase da observação, mas com concessão para a fase de regência". Por essa razão, as autoras discutem o papel da observação no estágio supervisionado de inglês e concluem: "confirmamos, pelos dados, que a observação da forma como tem sido realizada nas escolas não tem contribuído com o trabalho do professor, o que justifica a recusa e resistência dos mesmos para com estagiários" (BIAZI; GIMENEZ; STUTZ, 2011, p. 75).

Nesse mesmo trabalho, o que justifica a resistência das/os professoras/es a serem observadas/os é que a observação se constitui, para elas/es, como "fator de constrangimento", pois se sentem julgados/as aos olhos das/os professoras/es estagiárias/es; para eles/as, a observação transforma suas "salas de aula em meros espaços para o cumprimento de uma obrigação burocrática” (BIAZI; GIMENEZ; STUTZ, 2011, p. 71). Chama-me também muito a atenção o fato de a observação ser considerada oportunidade para as/os professoras/es em formação "saberem realmente a realidade, que é bem diferente da parte teórica” (BIAZI; GIMENEZ; STUTZ, 2011, p. 71). Essa separação entre teoria e prática que ocorre nas práticas de observação do estágio supervisionado foi uma das razões pelas quais apostei em desenvolver o estágio naquele semestre sem começar da maneira como tradicionalmente fazemos. $\mathrm{Na}$ observação, a teoria viria da universidade, local de produção de conhecimento, que vai à prática da escola a fim de conhecer como ela é feita e de que maneira se encaixa nos requisitos e pressupostos prévios sobre como ensinar. Identifico nessa postura o que Lander (2005) chama de "colonialidade do saber", isto é, a reprodução de uma visão de mundo que concebe o conhecimento como produzido apenas nos espaços legitimados de fazer científico aos moldes da racionalidade iluminista, ocidental e de modos de pensar euroeuacentrados. Assim, para o autor, a universidade reproduz a "herança colonial" em seus paradigmas de ensino e de conhecimento, reforçando a hegemonia cultural, política e econômica do ocidente. Para Mignolo (2014, p. 63), a universidade é fundamental não só na construção da colonialidade do saber, mas também em sua manutenção e gestão. 
Refletindo sobre isso, pensei em discutir com as/os professoras/es estagiários/as sobre como observar e como nossas observações são pautadas em nossas próprias experiências e histórias, estereótipos e preconceitos, como já havia feito em semestres anteriores. Entretanto, considerando que nossas observações são feitas a partir dos discursos e da historicidade que constroem nossas identidades (HALL, 2003) e entendendo a colonialidade impregnada nas práticas de observação tradicionalmente feitas, decidi que observar, enquanto atividade curricular do estágio, não faria parte da proposta daquele semestre em que estávamos integralmente na escola. Não bastaria tentar ressignificar a observação; o desejo era experimentar um rompimento maior. Porém, nossas expectativas e conhecimentos prévios sobre como o estágio supervisionado ocorre ou deve ocorrer estão sempre presentes. Já no início alguns/mas professores/as estagiárias/os perguntaram quando fariam as observações, sobre o que tivemos o seguinte diálogo:

Agnes: Professora, a gente não vai observar primeiro?

Mariana: Não, a gente não vai observar, como tradicionalmente é feito.

Agnes: Mas professora, a gente nem conhece as turmas, nem conhece direito os alunos, como a gente vai chegar lá e saber o que fazer, como que eles são? A gente nem viu como a professora faz ainda.

Mariana: Então, é por isso que nos nossos primeiros planejamentos a professora Sueli falou para a gente fazer planos para conhecer as turmas, para começar uma relação com os alunos, para ouvi-los.

Alice: Ah, mas se a gente observasse seria bem melhor para isso.

(Encontro de estágio em 25/08/17, audiogravação).

As perguntas das estagiárias Agnes e Alice mostram uma inquietação para conhecer, de antemão, os sujeitos que irão ensinar: "como eles são". Para conhecê-los, seria necessário "observar primeiro" ou ver "como a professora faz", como indaga Agnes. Observar aqui aparece como uma ação que oportunizaria esse conhecimento, que, por sua vez, seria suficiente para ajudar a iniciar os trabalhos de ensino com mais segurança ou propriedade. É interessante notar que observar parece já garantir conhecer: se observo, entendo como é e, então, conheço. Há aqui uma forte crença no olhar observador para entender e conhecer: sou sujeito capaz de, ao observar, entender e conhecer um determinado contexto. Essa parece ser uma postura colonial presente em nossa cultura de formação docente. Não 
foram assim nossas histórias de colonização? Colonizadores, ao adentrarem um determinado contexto, julgavam ser capazes de conhecê-lo a partir da observação que faziam; acreditavam fortemente na legitimidade de seus conhecimentos (iluministas, racionais) e suas identidades (brancos, europeus) para discernir, julgar, avaliar e, assim, descrever os novos contextos dos quais se apropriavam (QUIJANO, 2005).

A professora de inglês Sueli, ao discutir conosco sobre os conteúdos e temas das aulas que faríamos, recomendou:

\begin{abstract}
Mariana, eu acho que vocês podiam planejar aulas, inicialmente, para conhecer os alunos. Sabe, atividades que a gente dá para um primeiro encontro. Para vocês saberem como são os alunos. Fica à vontade para esses primeiros planejamentos. (Encontro de estágio em 18/08/17, audiogravação).
\end{abstract}

Sueli, em nenhum momento, sugeriu que suas aulas fossem observadas. Entretanto, ela se preocupou, sim, em nos ajudar a conhecer o contexto em que passaríamos a atuar como professoras/es. E não apenas isso; ela nos ensinou que conhecer o contexto não se dá apenas pela observação, mas pela pronta abertura para se relacionar com ele; por isso, sugeriu que fizéssemos planejamentos das primeiras aulas que, em si mesmos, já nos possibilitassem adentrar aos contextos das turmas da escola de maneira sensível. O ato de planejar nesse sentido e para esse fim já é, a meu ver, em si mesmo, abrir-se e tornar-se sensível para escutar e conversar com o contexto no qual atuaríamos ao longo daquele semestre. Seria, ao mesmo tempo, pôr em xeque nossa plena capacidade de, ao observar, apreender com nosso olhar quem o outro é; seria duvidar de um olhar "isento", entendendo que é somente na relação com o outro que podemos "conversar" com ele. Entendendo também que o objeto a ser conhecido não existe fora do olhar do sujeito que o conhece ou, como afirma Mignolo (2014, p. 63), que "é fundamental tomar consciência de que não se pode observar de fora do padrão colonial de poder".

Skliar (2006, p. 32), educador argentino, ressalta a importância de formar professores/as para "conversar". De maneira semelhante, Bohn (2008), Jordão, Martinez e Halu (2011) e Mastrella-de-Andrade e Pessoa (2019) discutem, no contexto brasileiro, como é relevante que a formação docente de línguas seja voltada para uma perspectiva relacional de ensino, isto é, uma abertura sensível para escutar e entender as complexidades contextuais dos espaços escolares e do ensino de línguas. Nesse sentido, 
também Quintero e Guerrero (2018, p. 84), a partir do cenário colombiano, falam de uma formação que nos torne "sensíveis ao contexto", isto é, que não se preocupe em simplesmente transmitir racionalidades fixas sobre ensinar e aprender línguas, mas que esteja aberta a perspectivas críticas que partam do contexto para entender as necessidades e construir possibilidades de ensino. Entendo que essas vozes de formadoras/es do cenário latinoamericano - vozes do Sul - mostram uma preocupação com modelos de formação docente pré-concebidos, fixos, advindos de países europeus e dos Estados Unidos, tradicionalmente detentores do que é falar, saber e ensinar a língua inglesa, como se as contingências contextuais locais fossem, sem problemas ou inconveniências, possivelmente adaptáveis a suas metodologias "universais". Vemos posições de resistência a tais modelos e a esse entendimento da universalidade de metodologias de países do Norte, o que nos possibilita desenvolver, criativa e criticamente, nossos próprios modos de ensinar línguas e de formar professoras/es, que estaria, portanto, para além de uma perspectiva de observar o cumprimento de determinados critérios metodológicos para aprender. Afinal, quem são as figuras de poder que detêm o saber sobre ensinar? No próximo episódio discuto um pouco mais essa questão.

\section{Episódio 3: "Você veio hoje? Mas eu já estou aqui!"}

Discuto, neste episódio, uma questão que, para mim, se interpôs como um conflito: sendo eu a professora formadora no estágio, qual é meu papel e como o desenvolvo? Esse é um questionamento com o qual convivo já há muito tempo, que advém de uma questão que acredito ser mais ampla: como de fato fazer parcerias com a escola para a formação docente? Como, no cotidiano de nossas práxis, decolonizar as relações entre universidade e escola?

Ao ler esse parágrafo anterior que acabo de escrever, bem como ao olhar para o material empírico registrado durante essa experiência do estágio integralmente na escola, chama-me a atenção a maneira como me descrevo: a professora formadora. Por que não considero que exista, nesse processo, outras professoras formadoras? Por que venho descrevendo que elas são as professoras de inglês da escola enquanto eu sou a professora formadora? Seria uma simples questão de identificação ou, para além disso, não consigo enxergar a presença de outras formadoras junto comigo no processo? Não seria esse o desejo (que acredito) que tenho em todo o tempo: parceria? 
O evento que transcrevo a seguir me aponta pistas para algumas reflexões sobre essas questões. Nesse dia, eu acabara de chegar à escola e me dirigira para a sala de aula de inglês, onde uma dupla de estagiárias/os ministraria aulas em uma turma do segundo ano naquela manhã. Assim que cheguei, ao cumprimentar a professora Sueli, tivemos a seguinte conversa, sobre o que depois escrevi a seguinte reflexão:

Mariana: Oi, Sueli, tudo bem? Eu vim observar a aula deles.

Sueli: Oi, Mariana. Você veio observar? A aula deles? Deles e a minha? Eu vou estar junto com eles. Eu já estou aqui.

(Observação de aula na escola em 29/09/17, Diário de campo.)

Essa foi uma interação que, de certa maneira, me paralisou. Fiquei sem saber como reagir e como entender, a princípio; anotei o que tinha ocorrido em meu diário e permaneci na sala fazendo observações somente durante o primeiro horário daquela manhã. Refleti que aquele lugar de observação era de Sueli. Era ela quem estava requerendo o lugar de supervisora. Era ela quem estaria com a professora e o professor estagiária/o que ministrariam as aulas naquele dia. Por que então eu havia ido até a escola para observar? Ao perguntar: "você veio observar? Deles e a minha?" e ao comentar "Eu vou estar junto com eles. Já estou aqui”, pode-se depreender uma crítica à minha posição colonialista de chegar para supervisionar, ignorando a presença de Sueli enquanto formadora. Sueli, assim como nós, também adentrouparaficar no estágio. Eu, porém, levei um tempo para reconhecer e legitimar esse seu movimento.

A distância que, em geral, os cursos de formação mantêm da escola promove um apagamento deste local enquanto espaço formativo para a docência. Esse apagamento é reforçado à medida que vemos apenas as atividades curriculares, como o estágio supervisionado em inglês, por exemplo, como meio estanque para uma aproximação inevitável com a escola. Segundo Borelli (2018) e Castro (2008), os estágios supervisionados são muitas vezes vistos como momentos da prática, isto é, de aplicação da teoria adquirida nas demais disciplinas desenvolvidas dentro da universidade. Essa separação entre teoria e prática está calcada em uma racionalidade moderna iluminista, advinda da ideia de que o fazer científico, por meio de seu rigor e do distanciamento entre sujeito que pesquisa e objeto pesquisado, produz um conhecimento isento, neutro, livre de contaminações contextuais (CAMERON et al., 1993). É nesse processo que a teoria ganha 
status e se sobrepõe à prática, como se pudessem em algum momento ser separadas; como se conhecedores/as pudessem ser dissociadas/os do ato de conhecer que empreendem. Essa separação, segundo discute Mateus (2009, p. 312), tem outros efeitos: encontramos aí "uma ruptura sujeito e objeto, consciência e realidade, instrumento e resultado, mundo da teoria e mundo da vida".

As buscas da universidade por aproximar-se da escola podem expressar, embora de diferentes modos, o desejo de romper com as dicotomias advindas da separação teoria e prática e as hierarquizações, injustiças e alienações consequentes. É nessa busca que aposto em um estágio supervisionado realizado integralmente dentro da escola, como venho discutindo. Canário (2000 apud NACARATO, 2016, p. 703) fala da necessidade de uma formação "sentada na escola", contrapondo-a a uma formação "centrada na escola". Esse é um entendimento que aponta para a escola como espaço formativo; a meu ver, nossas tradicionais opções pelo distanciamento e por desenvolver práticas formativas afastadas dos espaços geopolíticos da Educação Básica, sejam eles públicos ou privados, mostram nosso apego às colonialidades que idolatram o conhecimento ocidental colonial euroeuacentrado, que a todo o tempo dita para nós como ensinar e aprender línguas a partir do ideal de sucesso neoliberal globalizado que aceitamos acriticamente. Nesse sentido, apesar de buscar uma opção decolonial para a formação de professores/as de inglês (BORELLI, 2018; SILVESTRE, 2017) através de uma aproximação radical com a escola, a colonialidade permanece em nós - em mim -, como sempre discute Mignolo (2014).

Também em outros registros do material empírico gerado durante a experiência de estágio naquele semestre aparecem indícios da participação das professoras de inglês da escola como formadoras, não como meras receptoras de estagiárias/os. Transcrevo aqui dois exemplos:

Mariana, hoje o Ed veio dar aula daquele planejamento dele que a gente tinha visto. Mas ele estava muito nervoso. Eu percebi que ele estava muito nervoso. Então sugeri para ele se sentar, aguardar, ficar um pouquinho ali na sala para relaxar um pouco. Aí eu assumi o plano dele. Aquele planejamento. E pedi para que ele apenas observasse a aula. Eu achei melhor fazer assim, tanto para o bem dele quanto para o bem da sala, tá? Foi interessante, porque eu gostei do plano dele. Eles trazem uns textos muito legais para a aula. Acho melhor do que usar 
o livro demais, como eu faço, porque fica chato a aula. Então eu usei o plano dele.

(Marde, professora de inglês da escola. Mensagem via Whatsapp em 19/09/17).

Outra coisa que aprendi com essa situação foi dar ouvidos à professora da escola, a Sueli. Ela sempre comentava que na nossa aula a gente deixava os alunos muito tempo divididos em grupos, o que gera espaço pra muita conversa e nos faz perder o controle da turma; mas, confesso, eu não levava muito a sério e não procurava mudar nesse aspecto. Agora eu estou mais atenta.

(Kate, professora estagiária. Anotação no diário em 09/2018)

Entendo que a maneira como Marde se apropria do papel de supervisora e orientadora do estágio é que a leva a orientar o professor estagiário Ed a parar e observar naquele dia. Ao contrário do que mostram alguns trabalhos, onde o estágio é o cumprimento de etapas burocráticas de assinatura de documentos, horas de observação e regência de aulas de inglês (BORELLI, 2018; ROSENBERG, 2008), a maneira como buscamos desenvolver o estágio integralmente dentro da escola deu-nos identidades de pertença e, assim, espaços de agência. Ao ver como o professor estagiário estava nervoso durante a aula, Marde se apropria de seu planejamento (do qual ela já tinha conhecimento) e o coloca em posição de observar, "para o bem dele" e para "o bem da sala”, como afirmou ela. Essa apropriação, a meu ver, se dá pela compreensão de Marde de nosso adentrarparaficar na escola. Da mesma forma, ela também adentraparaficar no estágio, encontrando para si um lugar de agência (JORDÃO; BÜHRER, 2013). Entendo que o ato de adentrarparaficar advém de e promove identificações e pertencimentos. Foi quando adentramosparaficar na escola que outros sujeitos participantes do estágio naquele espaço também o fizeram e acharam para si responsabilidades dentro do processo de formação.

Sueli também se apropria do papel de formadora à medida que dá feedback para as/os professoras/es estagiárias/os sobre como foram suas regências, como assinala Kate no excerto acima. Kate a reconhece como alguém que entende da práxis realizada na escola, pois relata ter aprendido com a professora algo para o qual não se atentava antes; algo que diz respeito à dinâmica daquela sala de aula, daquele contexto, do qual entende quem o vivencia. Assim, foi somente ao longo do processo que fui percebendo que 
não estava sozinha como formadora: nossos papéis enquanto formadoras/ es estiveram em movimento em todo o tempo no ato e na atitude de adentrarparaficar na escola. A professora Marde não apenas se identificou como formadora, mas também como em formação, na medida em que relata ter aprendido com o plano do estagiário Ed, como transcrito no excerto anterior. Nas palavras de Borelli (2018, p. 14), há um reconhecimento que é fundamental para uma opção decolonial de formação de professoras/es:

é preciso reconhecer que não é apenas do espaço escolar que precisamos para a efetivação do estágio, precisamos, principalmente, dos saberes que circulam naquele espaço, dos conhecimentos de seus/suas professores/as que, ainda que temporariamente, participam conosco como formadores/as nesse processo.

\section{Algumas últimas palavras, mesmo com a impossibilidade de conclusão}

Neste artigo, discuti uma experiência de formação docente dentro de uma escola pública em uma perspectiva decolonial no que se refere a três aspectos: a maneira como o estágio é estruturado, o meu papel como professora formadora e o papel dos sujeitos da escola. No que se refere à estrutura tradicional do estágio, rompemos com a prática da observação de aulas enquanto o passo que deveria necessariamente anteceder o acesso das / os professoras/es estagiárias/os à regência. Ao invés da tradicional estrutura de observar para então conhecer (BORELLI, 2018), buscou-se dialogar com as turmas de alunas/os da escola a fim de entender o que esperavam das aulas de inglês e como elas podiam ser construídas, acreditando que o conhecer se daria nas relações construídas em sala de aula, não à distância através de observação.

No que se refere ao papel dos sujeitos da escola, a experiência de estágio integralmente desenvolvido dentro de uma escola pública permitiu o que chamo aqui de adentrarparaficar na escola. É no ato e na atitude de adentrarparaficar que se construiu a experiência decolonial de formação docente de que falo: ganhamos diferentes visões de quem são as/os alunas / os da escola e as professoras de inglês se tornaram também professoras formadoras. Adentrarparaficar implica encontrar para si lugar tanto na escola quanto no estágio. Não significa aceitar a escola como ela está, mas enxergarse implicado em suas realidades e, assim, relacionar-se com ela como quem, de alguma maneira, passa a pertencer ali. 
No que se refere ao meu papel como professora formadora, a experiência de estágio supervisionado em inglês integralmente dentro de uma escola pública implicou abrir mão do meu saber-poder, desistir de minha posição de quem "sabe" como ensinar a ensinar e de quem "sabe" melhor avaliar as diversas situações de ensino que vivenciam as/ os professores/as estagiárias/os sob minha orientação. De fato, não posso formar sozinha. Meu adentrarparaficar me move a uma compreensãoafeto de mim mesma e da comunidade formadora que construímos naquela temporada, como apresentei aqui, me impelindo a desistir de uma posição única de saber no contexto de formação docente de línguas e, assim, reconhecer as ignorâncias que igualmente me constituem.

Nos saberes construídos ao adentrarparaficar na escola, vejo o limite do meu conhecimento, isto é, do conhecimento da universidade, o qual represento. Novos conhecimentos construídos apontam para novas ignorâncias, tornando assim o potencial formador da parceria universidade-escola imprevisível e potencializado. A universidade não pode ser onipresente ou onisciente e precisa se reconhecer diante dessa impossibilidade. Professoras/es universitárias/os não podem formar sozinhas/os; não lhes seria possível. Nesse sentido, como afirma Sousa Santos (2007), não há unidade de conhecimento, não havendo também unidade de ignorância. É nesse cruzamento de conhecimentos e ignorâncias, ambos heterogêneos e interdependentes, que está a ecologia de saberes de que fala Sousa Santos (2007, p. 87). A meu ver, essa ecologia de saberes que se faz formativa é reconhecida e legitimada a partir do que aqui venho discutindo como um adentrarparaficar na escola.

\section{Agradecimentos}

Este trabalho é fruto de minha pesquisa de pós-doutorado na Universidade Federal de Goiás, sob a supervisão da Professora Rosane Rocha Pessoa, a quem agradeço imensamente pela parceria constante.

\section{Referências}

ANDRADE, M. P. A branquitude e a colonialidade na prática docente na educação básica (2000-2015). Revista da ABPN, Goiânia, v. 10, p. 238-264, 2018. Doi: https:// doi.org/10.31418/2177-2770.2018.v10.n00.p238-264 
ANDREOTTI, V. O. Renegotiating Epistemic Privilege and Enchantments with Modernity: The Gain in the Loss of the Entitlement to Control and Define Everything. Social Policy, Education and Curriculum Research Unit. North Dartmouth: Centre For Policy Analyses/UMass Dartmouth, 2013. Disponível em: https:// pdfs.semanticscholar.org/f1 fe/1d6eb35dd552a14295bf7ba5f7a796ac04e1.pdf. Acesso em: 12 ago. 2018.

BIAZI, T.; GIMENEZ, T.; STUTZ, L. O papel da observação de aulas durante o estágio supervisionado de inglês. SIGNUM, Londrina, v. 14, n. 1, p. 57-78, 2011. Doi: https://doi.org/10.5433/2237-4876.2011v14n1p57

BLOMMAERT, J. Discourse: A Critical Introduction. Cambridge: Cambridge University Press, 2005. Doi: https://doi.org/10.1017/CBO9780511610295

BOHN, H. I. Maneiras inovadoras de ensinar e aprender: a necessidade de des(re) construção de conceitos. In: LEFFA, V. J. (Org.). O professor de línguas estrangeiras: construindo a profissão. 2.ed. Pelotas: Educat, 2008. p. 123-132.

BORELLI, J. D. V. P. O estágio e o desafio decolonial: (des)construindo sentidos sobre a formação de professores/as de inglês. 2018. 223 f. Tese (Doutorado em Letras e Linguística) - Universidade Federal de Goiás, Goiânia, 2018.

BRASIL, Ministério da Educação. Secretaria de Educação Básica. Orientações Curriculares para o Ensino Médio: linguagens, códigos e suas tecnologias. Brasília, DF: Ministério da Educação, 2006. 1 v.

BRASIL. Conselho Nacional de Educação. Resolução no 2/2015, de $1^{\circ}$ de julho de 2015. Define as Diretrizes Curriculares Nacionais para a formação inicial em nível superior (cursos de licenciatura, cursos de formação pedagógica para graduados e cursos de segunda licenciatura) e para a formação continuada. Diário Oficial da República Federativa do Brasil: seção 1, Brasília, DF, n. 124, p. 8-12, 2 jul. 2015.

BRENNEISEN, E.; TARINI, A. M. Identidade, diferença e pluralidade: um olhar para a sala de aula. Linguagem \& Ensino, Pelotas, v. 11, n. 1, p. 81-99, 2008.

CAMERON, D.; FRASER, E.; HARVEY, P.; RAMPTON, B.; RICHARDSON, K. Ethics, Advocacy and Empowerment: Issues of Method in Researching Language. Language \& Communication, Oxford, v. 13, n. 2, p. 81-94, 1993. Doi: https://doi. org/10.1016/0271-5309(93)90001-4

CASTRO, S. T. R. Formação da competência do futuro professor de inglês. In: LEFFA, V. (Org.). O professor de linguas estrangeiras: construindo a profissão. 2. ed. Pelotas: EDUCAT, 2008. p. 307-322. 
COELHO, H. S. Experiências, emocões e transformações na educação continuada: um estudo de caso. 2011. 175 f. Tese (Doutorado em Estudos Linguísticos) - Faculdade de Letras, Universidade Federal de Minas Gerais, Belo Horizonte, 2011.

DAMACENA, M. M. R.; MASTRELLA-DE-ANDRADE, M. R. A construção da identidade de alunos/as da escola pública nos discursos de licenciandos/ as em Letras-Inglês. In: CONGRESSO DE INICIAÇÃO CIENTÍFICA DA UNIVERSIDADE DE BRASÍLIA, 23., 2017, Brasília, DF. Anais [...]. Brasília, DF: UnB, 2017.

DENZIN, N. K.; LINCOLN, Y. S. The Sage Handbook of Qualitative Research. London: Sage, 2005.

GASPERI, F. V. Heroes and Villains: A Report of a Project to Teach English for Teenagers. Revista Bem Legal, Porto Alegre, v. 6. n. 2, p. 46-56, 2016.

GOMES, N. L. Relações étnico-raciais, educação e descolonização dos currículos. Curriculo Sem Fronteiras, [s. l.], v. 12, n. 1, p. 98-109, 2012.

GROSFOGUEL, R. Para descolonizar os estudos de economia política e os estudos pós-coloniais: transmodernidade, pensamento de fronteira e colonialidade global. Revista Crítica de Ciências Sociais, Coimbra, n. 80, p. 115-147, 2008. Doi: https://doi.org/10.4000/rccs.697

HALL, S. Who Needs Identity? In: HALL, S.; DU GAY, P. (Ed.). Questions of Cultural Identity. London: Sage, 2003. p. 1-17.

IFA, S. Estágio supervisionado de língua inglesa: experiências significativas para a construção de conhecimentos sobre prática docente. Estudos Linguisticos e Literários, Salvador, n. 50, p. 100-119, 2014. Doi: https://doi.org/10.9771/2176-4794ell. v0i50.14814

JORDÃO, C. M.; BÜHRER, E. A condição de aluno-professor de língua inglesa em discussão: estágio, identidade e agência. Educação \& Realidade, Porto Alegre, v. 38, n. 2, p. 669-682, 2013. Doi: https://doi.org/10.1590/S2175-62362013000200018 JORDÃO, C. M.; MARTINEZ, J.; HALU, R. C. Formação desformatada: práticas com professores de língua inglesa. Campinas: Pontes, 2011.

KLEIMAN, A. Preciso "ensinar" o letramento? Não basta ensinar a ler e a escrever? Brasilia, DF: Ministério da Educação; Campinas: Unicamp; 2005. (Série Linguagem e Letramento em Foco).

KUMARAVADIVELU, B. Individual Identity, Cultural Globalization and Teaching English as an International Language: The Case for an Epistemic Break. In: ALSAGOFF, L.; RENANDYA, W. A.; HU, G.; MCKAY, S. (Ed.). Teaching English as an International Language: Principles and Practices. New York: Routledge, 2012. p. 9-27. 
LANDER, E. (Ed.). La colonialidad del saber: eurocentrismo y ciencias sociales, perspectivas latinoamericanas. Ciudad Autónoma de Buenos Aires: CLACSO, 2005. Disponível em: http://biblioteca.clacso.edu.ar/clacso/sur-sur/20100708034410/ lander.pdf. Acesso em: 10 ago. 2016.

LIMA, F. de F; SALES, L. C. As representações sociais do aluno de escola pública partilhadas por professores de língua inglesa que ensinam em escolas públicas e particulares de Teresina. Atos de Pesquisa em Educaşão, Blumenau, v. 2, n. 1, p. 106122, 2007.

MARQUES, J. L. Formação de professores reflexivos em serviço. In: PONTES, A. (org.). Educação e formação de professores: reflexões e tendências atuais. São Paulo: Zouk, 2004. p. 51-71.

MASTRELLA-DE-ANDRADE, M. R.; PESSOA, R. R. A Critical, Decolonial Glance at Language Teacher Education in Brazil: On Being Prepared to Teach. D.E.L.T.A., São Paulo, [S.1.], v. 35, n. 3, maio 2019. Doi: https://doi. org/10.1590/1678-460x2019350306. Disponível em: https://revistas.pucsp.br/ delta/article/view/44219. Acesso em: 11 ago. 2019.

MATEUS, E. Torres de babel e línguas de fogo: um pouco sobre a pesquisa na formação de professores de inglês. Revista Brasileira de Linguística Aplicada, Belo Horizonte, v. 9, n. 1, p. 307-328, 2009. Doi: https://doi.org/10.1590/S198463982009000100015

MENEZES DE SOUZA, L. M. T. Para uma redefinição de Letramento Crítico: conflito e produção de significado. In: MACIEL, R. F.; ARAÚJO, V. de A. (Org.). Formação de professores de línguas: ampliando perspectivas. Jundiaí: Paco Editorial, 2011. p. 128-140.

MIGNOLO, W. Educación y decolonialidad: aprender a desaprender para poder reaprender. [Entrevista cedida a] Facundo Giuliano e Daniel Berisso. Revista del IICE, Buenos Aires, n. 35, p. 61-71, 2014. Disponível em: http:/ / revistascientificas. filo.uba.ar/index.php/iice/article/view/1961/1807. Acesso em: 15 ago. 2018.

MOITA LOPES, L. P. Pesquisa interpretativista em Linguística Aplicada: a linguagem como condição e solução. D.E.L.T.A, São Paulo, v. 10, n. 2, p. 329-338, 1994.

NACARATO, A. M. A parceria universidade-escola: utopia ou possibilidade de formação continuada no âmbito das políticas públicas? Revista Brasileira de Educaşão, Rio de Janeiro, v. 21, n. 66, p. 699-716, 2016. Doi: https://doi.org/10.1590/S141324782016216636

NUNES, M. B. What Is the Soundtrack of My Life? An Internship in Group 92. Revista Bem Legal, Porto Alegre, v. 6, n. 2, p. 4-12, 2016. 
PESSOA, R. R. Movimentos críticos de uma prática docente. In: PESSOA, R. R.; SILVESTRE, V. P. V.; MONTE-MÓR, W. (org.). Perspectivas críticas de educação linguística no Brasil: trajetórias e práticas de professoras(es) universitárias(os) de inglês. São Paulo: Pá de Palavra, 2017. p. 185-198.

PUREZA, P. H.; ZANIOL, V. Culture and Consumerism in the Classroom. Revista Bem Legal, Porto Alegre, v. 6, n. 2, p. 75-83, 2016.

QUIJANO, A. Colonialidad del poder, cultura, y conocimiento em América Latina. Ecuador Debate, Quito, v. 44, p. 227-238, 1998.

QUIJANO, A. Colonialidad del poder, eurocentrismo y América Latina. In: LANDER, E. (ed.). La colonialidad del saber. eurocentrismo y ciencias sociales, perspectivas latinoamericanas. Ciudad Autónoma de Buenos Aires: CLACSO, 2005. p. 107-130.

QUINTERO, A. H.; GUERRERO, C. H. The (Re)Construction of Self Through Student-Teachers' Storied Agency in ELT: Between Marginalization and Idealization. In: YAZAN, B.; RUDOLPH, N. (Ed.). Criticality, Teacher Identity, and (In)Equity in English Language Teaching Issues and Implications. Amsterdam: Springer, 2018. p. 81-102. Doi: https://doi.org/10.1007/978-3-319-72920-6_5

RICHARDS, J. C.; LOCKHART, C. Reflective Teaching in Second Language Classrooms. Cambridge: Cambridge University Press, 1996.

ROSENBERG, A. J. O estágio burocrático e a formação do professor: paisagens de ação e paisagens de consciência na licenciatura em língua inglesa - um estudo de caso. 2008. 191 f. Dissertação (Mestrado em Estudos Linguísticos e Literários em Inglês) - Faculdade de Filosofia, Letras e Ciências Humanas, Universidade de São Paulo, São Paulo, 2008.

SOUSA SANTOS, B. Para além do pensamento abissal: das linhas globais a uma ecologia de saberes. Novos Estudos CEBRAP, São Paulo, v. 79, p. 71-94, 2007. Doi: https://doi.org/10.1590/S0101-33002007000300004

SOUSA SANTOS, B. A crítica da rãão indolente: contra o desperdício da experiência. São Paulo: Cortez, 2009.

SCHLATTER, M. O ensino de leitura em língua estrangeira na escola: uma proposta de letramento. Calidoscópio, São Leopoldo, v. 7, n. 1, p. 11-23, 2009.

SCHON, D. The Reflective Practitioner. How Professionals Think in Action. New York: Basic Books, 1983. 
SILVA, A. F.; SANTIAGO, M. L. T. Hi, Future Me! A Time in Class to Think about Past, Present and Future, in English. Revista Bem Legal, Porto Alegre, v. 6. n. 2, p. 295-304, 2016.

SKLIAR, C. A inclusão que é nossa e a diferença que é do outro. In: RODRIGUES, D. (org.). Inclusão e educação: doze olhares sobre a educação inclusiva. São Paulo: Summus, 2006. p. 15-34.

SMYTH, J. Teachers' Work and the Politics of Reflection. American Educational Research Journal, [S. l.], v. 29, n. 2, p. 267-300, 1992. Doi: https://doi. org/10.3102/00028312029002268

SÜSSEKIND VERÍSSIMO, M. L. Teatro de açoes: arqueologia dos estudos nosdoscom os cotidianos, relatos das práticas pedagógicas emancipatórias nas escolas. 2007. 235 f. Tese (Doutorado em Educação) - Faculdade de Educação, Universidade do Estado do Rio de Janeiro, Rio de Janeiro, 2007.

WALSH, C. Estudios (inter)culturales en clave decolonial. Tabula Rasa, Bogotá, n. 12, p. 209-227, 2010a. Doi: https://doi.org/10.25058/20112742.393

WALSH, C. Interculturalidad crítica y educación intercultural. In: VIAÑA, J.; TAPIA, L.; WALSH, C. (org.). Construyendo interculturalidad crítica. La Paz: Instituto Internacional de Integración del Convenio Andrés Bello, 2010b. p. 75-96.

ZEICHNER, K. M. Uma análise crítica sobre a "reflexão" como conceito estruturante na formação docente. Educação \& Sociedade, Campinas, v. 29, n. 103, p. 535-554, 2008. Doi: https://doi.org/10.1590/S0101-73302008000200012

ZEICHNER, K. M.; LISTON, D. Reflective Teaching: An Introduction. New York: Routledge: Erlbaum, 1996.

Data de submissão: 19/02/2019. Data de aprovação: 06/06/2019. 